\title{
Review
}

\section{Role of misfolding in rare enzymatic deficits and use of pharmacological chaperones as therapeutic approach}

\author{
Gioena Pampalone ${ }^{1}$, Silvia Grottelli ${ }^{1}$, Leonardo Gatticchi ${ }^{1}$, Emilia Maria Lombardi ${ }^{1}$, \\ Ilaria Bellezza ${ }^{1}$, Barbara Cellini ${ }^{1, *}$ \\ ${ }^{1}$ Department of Medicine and Surgery, University of Perugia, 06132 Perugia, Italy
}

\section{TABLE OF CONTENTS}

\author{
1. Abstract \\ 2. Introduction \\ 3. Protein misfolding and human disease \\ 4. Use of pharmacological chaperones as therapeutic approach in rare enzymatic deficits \\ 4.1 Gaucher disease \\ 4.2 Phenylketonuria \\ 4.3 Primary hyperoxaluria type I

\section{Conclusions} \\ 6. Author contributions \\ 7. Ethics approval and consent to participate \\ 8. Acknowledgment \\ 9. Funding \\ 10. Conflict of interest \\ 11. References
}

\section{Abstract}

Cells have evolved sophisticated molecular control systems to maximize the efficiency of the folding process. However, any subtle alteration of the environment or the protein can lead to misfolding or affect the conformational plasticity of the native states. It has been widely demonstrated that misfolding and/or conformational instability are the underlying mechanisms of several rare disorders caused by enzymatic deficits. In fact, disease-causing mutations often lead to the substitution of amino acids that are crucial for the achievement of a folded conformation, or play a role on the equilibrium between native-state conformers. One of the promising approaches to treat conformational disorders is the use of pharmacological chaperones (PCs), small molecules that specifically bind a target protein and stabilize a functional fold, thus increasing the amount of functionally active enzyme. Molecules acting as PCs are usually coenzymes, substrate analogues behaving as competitive inhibitors, or allosteric modulators. In this review, the general features of PCs are described, along with three examples of diseases (Gaucher disease, Phenylketonuria, and Primary Hyperoxaluria) in which this approach is currently under study at preclinical and/or clinical level.

\section{Introduction}

The comprehension of the process that allows an unfolded polypeptide chain to acquire the native state, as well as of the role of intracellular systems that assist proteins during the folding process, is a difficult task, as recently reviewed in [1]. The Anfinsen's experiment on the refolding of ribonuclease A demonstrated fifty years ago that the native structure of a protein is determined by amino acids sequence [2], but the efficiency of the folding process is also strongly influenced by the surrounding environment [3]. Protein folding is an exergonic process, because the enthalpic and entropic changes associated with the achievement of a folded structure reduce free energy of the native state with respect to that of the unfolded state $[4,5]$. In addition, the process usually occurs very rapidly, in particular in the case of small proteins [6]. Starting from the Levinthal's paradox highlighting that it would be impossible even for a short polypeptide chain to fold in a timeline of seconds by the simple trial of all possible conformations, many studies combining in silico and in vitro experiments have been focused on the understanding of the thermodynamics and the kinetics of the folding process [1, 7-9]. 
The current view of protein folding is based on the concept of a free energy landscape represented as a folding funnel (Fig. 1). The wideness of the funnel is the entropy, i.e., the number of possible conformations of the chain, while the height represents the free energy. The polypeptide fluctuates in a conformational landscape where the acquisition of favorable conformations, i.e., those characterized by a lower free energy, drive the chain down in the funnel until the native state $[1,9]$. For many proteins, the difference in free energy between the unfolded and the folded state is very low, so that any small alteration of the protein chain and/or of the environment can have a great impact on folding efficiency [1]. In addition, more sophisticated theories and models should be applied when considering the folding of multi-domain protein, which can also fold independently and/or in a sequential way [10]. The presence of folding building blocks, named "foldons" and able to unfold and refold as whole units, has been also advanced [11].

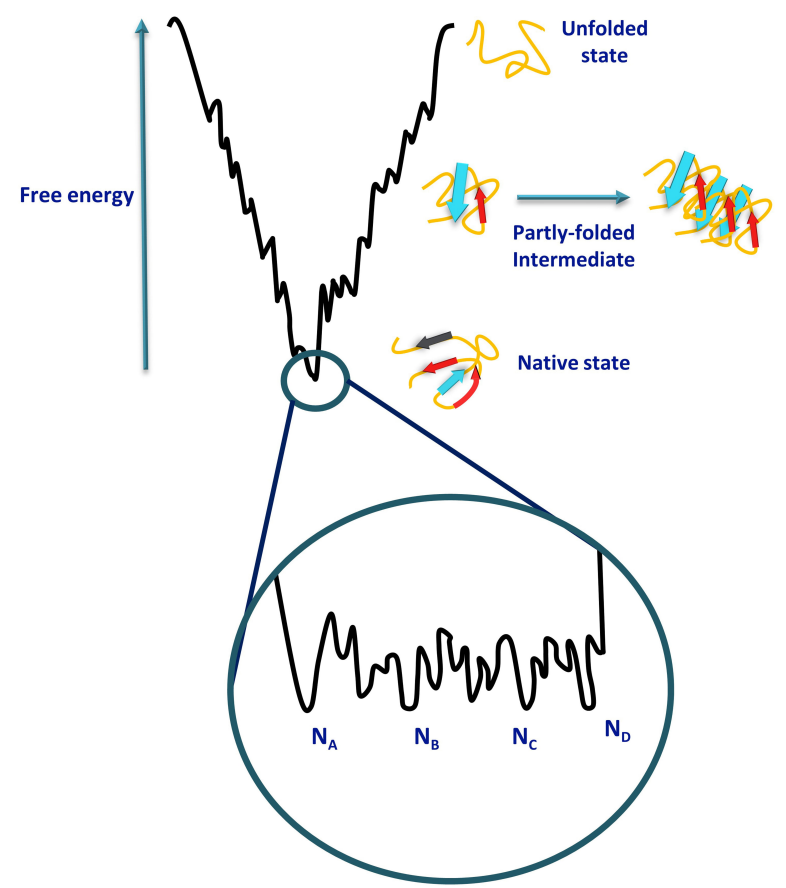

Fig. 1. Schematic representation of the folding funnel. A protein in the unfolded state can reach its native conformation through a process governed by changes in terms of entropy (represented by the wideness of the funnel) and free energy. In the flat bottom different native conformers are displayed $\left(\mathrm{N}_{A-D}\right)$. The formation of a partly-folded intermediate is also shown.

In the past, most studies on the folding pathway of globular proteins have been guided by two paradigms: (1) the polypeptide chain follows its route in a folding funnel leading to a unique native structure, which represents the most stable conformation under physiological conditions. (2) the major driving force for folding is the "hydrophobic burst”, i.e., the interaction between residues showing hy- drophobic (aliphatic or aromatic) side chains. Therefore, misfolding mainly arises from intermediates exposing hydrophobic surfaces $[12,13]$. Some proteins generate a folding intermediate named molten globule, in which the chain has acquired the secondary structure elements, but most hydrophobic patches are still exposed on the surface, thus explaining why it can be prone to aggregation [14]. In the final steps of the folding process the protein undergoes the complete acquisition of the tertiary and, when present, quaternary structure, thanks to subtle rearrangements also involving amino acid side chains on the surface [15]. Although the formation of a molten globule is often observed, in vitro studies have shown that intermediates forming during the folding process of globular proteins can be differently structured, and they can differently populate depending on the environment in which the protein folds [16]. This concept has generated the view that the folding funnel of most proteins is "roughed". In fact, during the process the chain can be entrapped in local energy minima with a high energy barrier that needs to be overcome to reach the global free energy minimum of the native conformation [17]. The formation of partly-folded intermediates also makes the protein susceptible to non-native interactions that can promote aggregation and/or degradation, thus leading to misfolding [10].

The most recent advances in protein chemistry, along with the use of sophisticated structural analyses, have allowed not only to expand the picture of the general principles underlying protein folding, but also to implement our knowledge of the properties of the native state. In fact, the native structure can no longer be considered an arrival point because native proteins show a significant structural plasticity, and fluctuate among various conformers $[18,19]$. The latter finding has converted the idea of a sharp folding funnel leading to a unique shape, to that of a flat funnel where an ensemble of native conformers coexists (Fig. 1). Conformational plasticity can promote protein dynamics and adaptability to changes in external conditions, or it can be crucial for the interaction with a particular ligand or binding partner. In small single-domain proteins, the population of rapidly interconverting native conformers has been observed and recently related to the intrinsic fuzziness of some proteins that do not acquire a fully optimized structure in order to expand the ensemble of possible structures and therefore functions that a protein can perform [20]. In contrast to partly-folded intermediates, which usually expose hydrophobic surfaces, native conformers of small proteins can differ from each other for changes mainly involving residues exposed on the surface of the protein. Thus, their association to form aggregates and/or interaction with binding partners is expected to be mainly mediated by electrostatic forces [21]. The consequence is that the surface likely influences the stability of a protein by possibly shifting the equilibrium toward potentially noxious conformers prone to local unfolding [22]. 
An extreme side of protein conformational plasticity is exemplified by intrinsically disordered proteins, which acquire a folded conformation only in the presence of a binding partner, or by globular proteins carrying intrinsically disordered regions (IDRs) [13]. It has been estimated that about $22 \%$ of the human proteome is constituted by proteins showing IDRs [23]. The presence of IDRs is more common in multi-domain proteins of eukaryotes as compared with prokaryotes [24]. Although the role of IDRs of soluble globular proteins is poorly understood, many evidences suggest that they could be able to integrate and transmit a wide range of intracellular signals, mediate protein-protein interactions or post-translational modifications [19].

In the case of multi-domain proteins, the folding process and the stability of the native state can be even more complex. Indeed, besides the moonlighting properties of a growing number of proteins including metabolic enzymes [25], which highlight a functional plasticity, new categories in the field of conformers of the native state have been introduced taking into account the possibility to interconvert among conformers generated by large motions of domains or entire subunits. They include (i) proteins showing short chameleonic sequences that can fold into an $\alpha$ helic or a $\beta$-sheet. (ii) morpheeins, which in solution interconvert among various oligomeric forms possibly resulting in different functions. (iii) metamorphic proteins, which can adopt different folded states that reversibly interconvert $[26,27]$. The latter group include proteins involved in important processes such as cell cycle regulation, solute transport, gene expression, as exhaustively reviewed [2830].

Finally, the global picture of the protein folding process should consider that the events occurring in a cell may differ from those occurring in vitro in many respects including: (i) the vectorial protein synthesis, which allows cotranslational folding to occur. (ii) the presence of a crowded environment, which can promote aggregation. (iii) the influence of subcellular import, which can occur on the unfolded or the folded state depending on the organelle, and of binding partners, that can promote correct folding. (iv) the action of various classes of molecular chaperones, proteins that use the free energy of ATP hydrolysis to help the folding process by inhibiting or reverting aggregation, promoting the achievement of the native conformation, and/or allowing the degradation of misfolded intermediates [3135].

\section{Protein misfolding and human disease}

The global processes of synthesis, recycling, modification, or degradation of the proteome of a cell are governed by molecular complexes that are involved into protein homeostasis regulation (proteostasis) [36]. Proteostasis is crucial for cell survival and for cell response to any change occurring in the surrounding environment and represent a pivotal mechanism against any kind of external stimuli, including oxidative stress [37]. The proteostasis network controls critical phases in proteins building, such as correct folding and localization, allowing to produce proteins when and where they are needed. Through its crucial role in cellular proteome organization, the proteostasis network also exerts effects that influence the organization at tissue and organism level [38]. Despite the presence of numerous and effective control systems, the accumulation of incorrectly folded or misfolded proteins is not uncommon. Although cells have evolved sophisticated systems to promote folding, any subtle alteration of the environment and/or the polypeptide chain can shift the equilibrium from the native state to an unfolded or partly-folded state, thus leading to misfolding [35]. Protein misfolding in most cases arises from the population of partly-folded intermediates that can be prone to self-associate, are more susceptible to be degraded by the intracellular quality control systems or can be mistargeted to a wrong compartment [22, 39]. However, numerous evidences suggest that also native or native-like intermediates can trigger misfolding. This can occur in the presence of an environmental changes such as increased oxidative stress, altered $\mathrm{pH}$, viscosity or osmolarity of the medium, as well as of a protein change involving surface residues, such as post-translational modifications, or inherited/acquired mutations [22, 40, 41]. In the case of multi-domain proteins, a dysregulation of proteostasis can also arise from interferences within large conformational changes accompanying the interconversion of the different native states conformers or from the appearance of moonlighting properties [42]. An example of this mechanism has been provided by mutations associated with ALAD porphyria, which changed the equilibrium between distinct morpheein forms endowed with different activity. Thus, the classical view of the pathogenesis of misfolding disorders should be expanded to include alteration influencing not the folding process itself, but the conformational plasticity of the native state [43].

Increasing evidences indicate that protein misfolding or altered native state stability is the underlying mechanism of many human disorders, comprising neurological, metabolic, and also infectious diseases [44, 45]. Examples of human diseases associated with protein misfolding are reported in Table 1. In general, two different scenarios can describe the pathogenesis of conformational diseases: (1) loss-of-function, when the effects of misfolding are related to the loss of the functionality specific of the misfolded protein. A typical example is represented by enzyme deficits, where the loss of the catalytic activity of a misfolded enzyme can lead to substrate accumulation, product deficiency, or generation of secondary metabolites [34, 46]. (2) gain-of-function, when misfolded proteins generate species, often ordered aggregates, that become toxic for the cell. The latter possibility is typically ob- 
Table 1. Example of misfolding diseases displaying a Loss-of-Function (LoF) or Gain-of-function (GoF) pathogenesis.

\begin{tabular}{|c|c|c|c|c|c|}
\hline Rare disease & Genetics & $\begin{array}{l}\text { Molecular } \\
\text { pathogenesis }\end{array}$ & Compartment & Protein involved & Main sympthoms \\
\hline Huntington disease & $\begin{array}{l}\text { Autosomal domi- } \\
\text { nant }\end{array}$ & LoF and GoF & Nucleus and Cytosol & Huntingtin & $\begin{array}{l}\text { Neurodegeneration, incoordination, and be- } \\
\text { havioural difficulties }\end{array}$ \\
\hline Cystic fibrosis & $\begin{array}{l}\text { Autosomal reces- } \\
\text { sive }\end{array}$ & LoF & ER & CFTR & $\begin{array}{l}\text { Degeneration of lung function, Sinusitis, In- } \\
\text { ability to exercise, Male infertility, and re- } \\
\text { peated infections }\end{array}$ \\
\hline Gaucher disease & $\begin{array}{l}\text { Autosomal reces- } \\
\text { sive }\end{array}$ & LoF and GoF & ER & $\beta$-Glucocerebrosidase & $\begin{array}{l}\text { Anemia, thrombocytopenia, hep- } \\
\text { atosplenomegaly, aseptic necrosis of } \\
\text { bone, and osteoporosis }\end{array}$ \\
\hline Phenylketonuria & $\begin{array}{l}\text { Autosomal reces- } \\
\text { sive }\end{array}$ & LoF & Cytosol & PAH & $\begin{array}{l}\text { Mental retard, tremors, hyperactivity, and } \\
\text { skin conditions (eczema) }\end{array}$ \\
\hline Parkinson disease & $\begin{array}{l}\text { Autosomal dom- } \\
\text { inant/recessive } \\
\text { and acquired }\end{array}$ & LoF and GoF & Cytosol & $\alpha$-Synuclein & $\begin{array}{l}\text { Tremor, rigidity, slowness of movement, } \\
\text { postural instability, difficulty with walking, } \\
\text { and nausea }\end{array}$ \\
\hline $\begin{array}{l}\text { Primary hyperox- } \\
\text { aluria type I }\end{array}$ & $\begin{array}{l}\text { Autosomal reces- } \\
\text { sive }\end{array}$ & $\mathrm{LoF}$ & Peroxysome & AGT & $\begin{array}{l}\text { Nephrolithiasis, nephrocalcinosis, and pro- } \\
\text { gressive renal failure }\end{array}$ \\
\hline Fabry disease & $\begin{array}{l}\mathrm{X} \text {-linked reces- } \\
\text { sive }\end{array}$ & $\mathrm{LoF}$ & Lysosome & $\alpha$-Galactosidase A & $\begin{array}{l}\text { Hypohidrosis, heat intolerance, corneal } \\
\text { opacities, arrhythmias, and renal insuffi- } \\
\text { ciency }\end{array}$ \\
\hline
\end{tabular}

AGT, Alanine: glyoxylate aminotransferase; CFTR, Cystic fibrosis transmembrane conductance regulator; PAH, Phenylalanine-4-hydroxylase.

served in neurodegenerative diseases, where tissue damage is caused by fibrillary aggregates rich in $\beta$-structure of proteins or small peptides [22, 47]. A third possibility exists, in which cellular damage is triggered by the molecular response of the cell aiming at restoring proteostasis. Indeed, when the alterations cannot be rescued, signaling pathways are activated that cause cell death by usually inducing apoptosis [48].

\section{Use of pharmacological chaperones as therapeutic approach in rare enzymatic deficits}

The increasing access to genetic screenings and family segregation studies has allowed the identification of many mutations that have been validated as pathogenic and associated with rare diseases. In the United States, a rare disease is a condition that affects less than 1 in 200,000 people, while in the European Union a disease is classified as rare if it affects less than that 1 in 2000 people [49]. A large subgroup of rare diseases is represented by enzymatic deficits, which are usually characterized by a loss-of-function pathogenesis. Disease-causing mutations can lead to various effects at phenotypic level, spanning from the complete loss of a protein product, the generation of truncated or defective variants, or alterations at sites of post-translational modifications, or protein-protein interactions [50, 51]. In the frequent case in which mutations lead to a missense change, a pathogenic variant is produced that can display a wide spectrum of structural and/or functional defects [52]. Studies performed in the last years agree upon the finding that misfolding is a common mechanism underlying the loss-of-function of enzymes involved in rare diseases [53, 54]. As such, the loss-of-function is caused by the absence of an adequate amount of an otherwise catalytically-active variant, due to a conformational defect that can promote intracellular aggregation, increased degradation, aberrant subcellular localization, or an aberrant regulation hampering the conversion into active states [34, 45]. Upon this discovery, many efforts have been dedicated to the identification of strategies able to rescue for the effects of destabilizing mutations leading to misfolding. One of those is based on the use of pharmacological chaperones (PCs) [55].

The use of inhibitors to increase the levels of misfolded proteins has been first demonstrated by the pioneering work of Fan JQ and coworkers in 1999, who discovered that a competitive inhibitor of $\alpha$-galactosidase $\mathrm{A}$ at sub-inhibitory concentrations was able to rescue for the Q279E and R301Q mutations in lymphoblasts of Fabry disease patients [56]. The term PC has been then introduced by Morello and co-workers, who discovered smallmolecules antagonists of the vasopressin receptor able to rescue folding-defective variants [57]. Since then, several studies have been performed to identify PCs for many proteins, including enzymes associated with rare diseases, as well as to better understand their mechanism of action [54, 58, 59]. PCs should not be confused with molecular chaperones or chemical chaperons [60]. Molecular chaperones include a large group of endogenous proteins that assist protein folding in a non-specific way and prevent aggregation, thus guaranteeing proteostasis [36], while chem- 
ical chaperones are small osmolytes that help the folding process in a non-selective manner by a still debated mechanism probably related to a change in the structure of water that can force productive folding [44, 61]. Notwithstanding the similar final effect of promoting the acquirement of the native structures, PCs differ from chemical chaperones because they specifically target a protein prone to misfolding [59]. PCs cause a thermodynamic stabilization of the protein, thus shifting the equilibrium toward the folded and functional conformation [62]. They usually bind to specific domains or inter-domain regions and stabilize the overall structure by providing a molecular scaffold around which mutant or misfolded proteins can assume their threedimensional structures [34, 63]. From a thermodynamic point-of view, the mechanism of action of PCs can be understood in the light of the thermodynamics of protein folding. Indeed, the energy variation of the folding process can be so small that even subtle amino acid changes affecting the overall stability of an enzyme can narrow the $\Delta \mathrm{G}$ unfolded-folded state to a degree that phenotypically impairs the production of sufficient amounts of functional enzyme. The interaction of the protein with a PC shifts the equilibrium toward the native states by generating a thermodynamically stable complex, thus providing a positive energetic contribution to the folding process. The latter effect can arise from the binding itself, or from an indirect action on the stabilization of the quaternary structure [64]. In some cases, the increase in the concentration of the folded protein also promotes its correct intracellular targeting, because the protein can successfully be recruited to the proper subcellular localization [65]. This is especially important for proteins that are imported in the ER, destined to the plasma membrane, or secreted in the extracellular space [66]. In proteins showing significant structural plasticity in the native state, PCs can also influence the equilibrium among the different possible conformers, e.g., stabilizing the more active and/or stable one under physiological conditions, possibly through a mechanism of conformational selection as proposed in the case of molecular chaperones [67].

Although their action is protein and mutationspecific, different studies demonstrate that they can be efficacious for more than $50 \%$ of missense mutations [68]. For this reason, PCs therapy offers a promising alternative approach for rare diseases for which only organ transplant or enzyme replacement are available [69]. Compounds acting as PCs identified so far have different protein targets including secreted proteins, transcriptions factors, ion channels, $\mathrm{G}$ protein-coupled receptors, and disease-causing enzymes such as in particular lysosomal hydrolases [54, 59, 70-73]. The general rules that defined first generation PCs are: (i) they target proteins bearing mutations that make the overall structure unstable but do not affect the functional properties. (ii) they must be specific for the target protein, e.g., used at very low concentrations (in the nanomolar range), and in the case of enzymes they must bind at the active site [74]. Enzyme ligands effective as PCs are either vitamin derivatives functioning as coenzymes, or substrate analogues acting as competitive inhibitors [65]. The rationale at the basis of the action of these two classes of PCs is shown in Fig. 2A,B. It is known that when a coenzyme binds to the apoprotein not only has a prosthetic role, by participating to the catalytic pathway, but can also exert a chaperone role, by inducing an overall stabilization of the native structure or by promoting the folding of partly-folded intermediates [75-77]. As for substrate analogues, the use of PCs can be considered a counterintuitive approach [62]. They behave as competitive inhibitors of the target enzyme, bind the active site with high specificity and promote folding, then dissociate from the target protein in the presence of the physiological substrate, thus restoring activity. Recently, the term "second-generation PCs" has been introduced to indicate non-inhibitor molecules, as allosteric modulators able to promote folding. The main difference with respect to "first-generation PCs" is their binding to an enzyme pocket far from the active site [72, 73] (Fig. 2C). In some cases, such as for G-protein coupled receptors, PCs working as allosteric modulators can represent a more promising approach, as compared with classical active site ligands, because they do not compete with the physiological substrate, thus minimizing untoward inhibition effects [73].

We focused this review on three examples of rare diseases due to enzymatic deficits for which a therapy with molecules acting as PCs has been investigated. Gaucher disease has been one of the first disorders for which the use of substrate analogues as PCs has been proposed and tested at clinical level. Phenylketonuria represents a paradigmatic example of the role of coenzymes as PCs, as well as of the development of second-generation PCs. Primary Hyperoxaluria Type I is a disease in which both coenzymatic forms and substrate analogues have been tested for their chaperone activity.

\subsection{Gaucher disease}

Gaucher disease (GD, OMIM 230800) is classified as lysosomal storage disorder (LSD). Lysosomes are organelles involved in the catabolism of different class of molecules such as cholesterol, glycoproteins, glycosphingolipids, peptides, and glycogen, thanks to the presence of more than 50 hydrolases in their matrix [78, 79]. If one of these metabolic pathways is blocked by the loss of a specific enzyme activity, the substrate accumulates in the lysosome, resulting in enzyme-specific clinical manifestations [80]. Most LSDs show autosomal recessive inheritance, with a small percentage inherited as X-linked trait [78]. Although each LSD is rare, their prevalence as a group can be as high as $1 / 1000$, in particular in some populations such as Ashkenazi jewish [81, 82]. The use of PCs has emerged as promising approach for the treatment of various LSDs, including in particular GD, Fabry disease, and Krabbe disease [83]. 

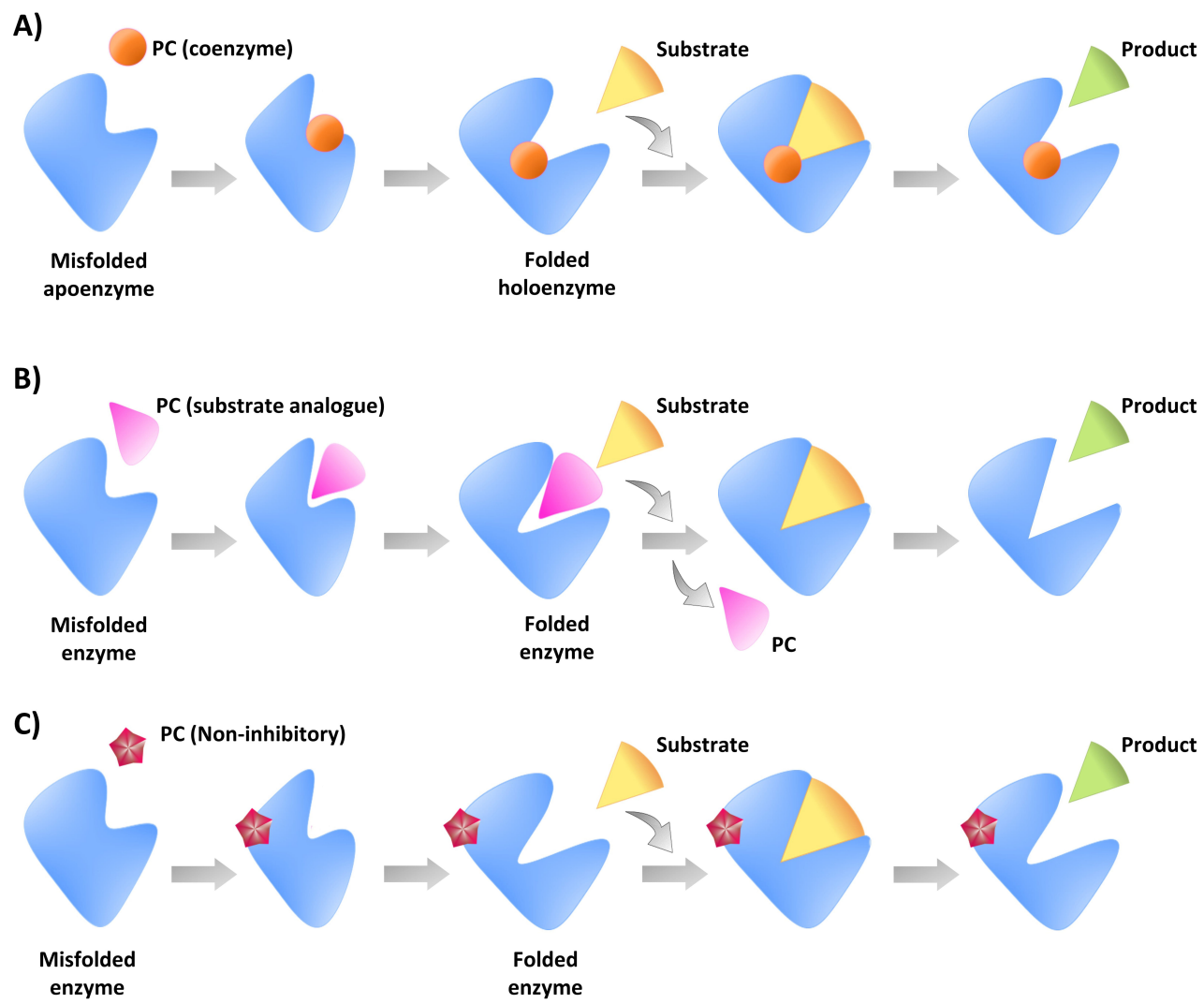

Fig. 2. Schematic representation of the PCs mechanism of action. (A) Coenzymes act on misfolded apoenzymes, inducing the proper folding of the holoenzyme and restoring its catalytic activity. (B) Substrate analogues can behave as competitive inhibitors and bind the active site of misfolded enzymes, promoting the achievement of the folded state. In the presence of the physiological substrate the PC dissociates, and the enzyme activity is restored. (C) Second-generation PCs bind as allosteric ligands far from the active site and promote correct folding, or stabilize an active conformation of a protein through conformational selection.

GD is the most common and the most studied LSDs. The disease shows an autosomal recessive inheritance and is due to mutations in the GBA1 gene encoding $\beta$ Glucocerebrosidase (GBA) [80]. This enzyme is activated by saposin $\mathrm{C}$ and hydrolyzes the sphingolipid glucosylceramide into glucose and ceramide. Pathogenic mutations cause a functional deficiency of GBA leading to the accumulation of undigested glucosylceramide in lysosomes that in turn causes impairment of autophagy, mitochondrial dysfunction, and inflammation [80, 84]. In particular, substrate accumulation is observed in macrophages and they become the so-called Gaucher cells, in which the high concentration of fibrillar or aggregated structures gives rise to a wizened aspect $[85,86]$. Three types of GD are known, based on their clinical features and in particular the involvement of central nervous system manifestations. GD Type I accounts for most cases and is considered as non-neuronopathic, although the development of neurological symptoms can develop later in life. Type II is the most severe form, also defined as neuronopathic infantile, cerebral, or perinatal lethal. The estimated life expectancy is about 3 years, because of severe neurological complications. Type III is of- ten confused with Type-I, because of the similarity in symptoms at the beginning, but then progresses with neurological involvement within the second decade of life [86]. It has been reported that the heterozygosis for mutations in the GBA1 gene typical of GD are also associated with an increased risk of Parkinson's disease [87] or with the possibility to develop different forms of cancer [84]. Indeed, Parkinson-like symptoms have been also found as a possible complication in GD Type I, probably dependent on an inverse relationship between GBA and $\alpha$-synuclein levels $[88,89]$.

Two specific therapeutic approaches are currently available for the treatment of GD: (1) Enzyme Replacement Therapy (ERT), in which recombinant GBA is administered intravenously to rescue the enzyme deficit. Approved pharmaceutical formulations are imiglucerase (Cerezyme ${ }^{\circledR}$, Sanofi-Genzyme); velaglucerase (Vpriv ${ }^{\circledR}$, Shire) and taliglucerase (Elelyso®, Pfizer). (2) Substrate Reduction Therapy (SRT), in which a small molecule is employed as a weak inhibitor of glucosylceramide synthase to reduce the burden of gkycosylceramide. Available drugs are $\mathrm{N}$ butyl-a-deoxynojirimycin (Miglustat, Zavesca ${ }^{\circledR}$, Actelion) 
and Eliglustat (Cerdelga ${ }^{\circledR}$, Sanofi-Genzyme) [86, 90]. Although all these treatments have proven useful and quite well tolerated by GD patients, they show high costs and are not effective against the neuropathic forms of the disease, thus prompting for the search of new approaches. In this regard, the analysis of disease pathogenesis has revealed that among the hundreds of GD-causing mutations, many are missense changes leading to the loss of GBA function by interfering with the folding process of the protein and lead to various effects including premature degradation, aggregation, or retainment in the ER [91]. This is true particularly for the L444P mutation, one of the two most common and associated with neurological impairment [92]. Therefore, the possibility to identify PCs specifically designed to facilitate folding, trafficking to lysosomes and function of mutant GBA has been attractive. PCs also have the potential to prevent or attenuate other cellular responses, including ER stress and the unfolded protein response that can lead to apoptosis and other inflammatory consequences [93].

Many in vitro studies also including highthroughput screening campaigns have been performed to identify small molecules as PCs in GD. Most are activesite specific ligands and reversible competitive inhibitors of GBA. Good candidates belong to the iminosugars family, inhibitors of the enzyme that also display chaperone activity when used at sub-inhibitory concentrations [94, 95]. $N$-nonyldeoxynojirimycin has been one of the first molecules identified, but showed poor selectivity, being not able to distinguish between $\alpha$ - and $\beta$-glucosidases [78]. Therefore, derivatives with a sp ${ }^{2}$-iminosugar structure were synthetized and they were found to be endowed with a higher selectivity against GBA [96, 97]. Isofagomine was also considered a promising candidate based on in vitro and in vivo studies [98, 99]. Tested in patients with the commercial name of Plicera ${ }^{\circledR}$ (isofagomine D-tartrate), isofagomine showed efficacy in phase I trials, but then failed in phase II trials, which did not reveal significant clinical improvements in patients without previous history of ERT (Trial ID NCT00433147, NCT00446550). Since the failure in clinics was mainly attributed to the high hydrophilicity of iminosugars, attempts have been made to generate substituted forms that showed effectiveness in fibroblasts of patients [100]. An attempt in this direction involved the synthesis of alkylated trihydroxypiperidine compounds. Experiments performed in patient fibroblatsts have shown that one hit compound is effective in rescuing for the N370/RecNcil but also the L444P mutation in fibroblasts derived from Gaucher patients compound heterozygous for the N370/RecNcil mutations and homozygous for the L444P mutation, the latter associated with neurologic impairment [101]. Among non-iminosugar molecules, Ambroxol, commercially available as an expectorant drug for newborns, is a mixed-type $\mathrm{pH}$-dependent inhibitor of GBA able to cross the blood-brain barrier, thus possibly useful also against the neuropathic forms of the disease. Am- broxol enhanced GBA activity in patients-derived fibroblasts and lymphoblasts [102]. Its effectiveness in nonhuman primates and patient-derived macrophages has been also reported [103, 104]. After some encouraging results in a pilot study no large clinical trials have been undertaken, and the drug has been used as off-label treatment [105]. An investigator-based registry recently published suggested a re-evaluation of the use of Ambroxol as a safe and cheap option for GD patients, although a wider and placebo-controlled study would be necessary to obtain approval and overcome the current limitation to prescriptions by physicians [106].

Recently, researchers have been focused on the possibility to identify second generation PCs able to stabilize GBA without interfering with the hydrolytic activity. This possibility has been raised after the identification of an allosteric binding site on the protein [107]. Several molecules have been identified [108, 109]. Under this perspective, the L-iminosugar series have also received attention because while D-iminosugars act as competitive inhibitors, the L-enantiomers are often found to be non-competitive inhibitors of GBA. L-iminosugars have proven effective in fibroblasts derived from N370S homozygous GD patients [110]. Non-inhibitory PCs represent a promising option in GD, because many active-site directed molecules failed in clinical trials probably as a consequence of an unfavorable balance between inhibitory versus chaperone behavior. New cellular models for pre-clinical testing and appropriate clinical trials will be necessary for a rapid development of effective drugs [111].

\subsection{Phenylketonuria}

Phenylketonuria (PKU, OMIM 264600) is an autosomal recessive disease caused by an error in amino acid metabolism. The prevalence is different around the world, from 1:10000 in Europe, to 1:15000 in USA. In some countries like Turkey the prevalence is higher (1:4000), because of consanguineous marriages within the population [112]. This disease is mostly diagnosed in the first days of life, through a blood test followed by genetic analysis indicating the presence of a pathogenic mutation in the gene encoding phenylalanine hydroxylase (PAH). $\mathrm{PAH}$ is a hepatic enzyme that catalyzes the rate-limiting step of dietary phenylalanine (Phe) catabolism, leading to the production of tyrosine $[77,113]$. In the absence of PAH, Phe accumulates in the bloodstream mainly leading to neurological symptoms, such as mental retardation, motor disorders, and depression, as well as other symptoms, such as eczematous rush, seizures, and autism [114]. The classification of PKU severity is based on the blood Phe concentration. The normal range of concentration is $50-110 \mu \mathrm{mol} / \mathrm{L}$. Concentrations of $120-600 \mu \mathrm{mol} / \mathrm{L}$ are classified as hyperphenylalaninemia, while levels of $600-1200 \mu \mathrm{mol} / \mathrm{L}$ are classified as mild phenylketonuria. Classic PKU is associated with levels of blood Phe above $1200 \mu \mathrm{mol} / \mathrm{L}$ [112, 115]. 
PAH is a homotetrameric cytosolic enzyme of 50 $\mathrm{kDa}$ subunits that catalyzes a monooxygenase reaction requiring molecular oxygen, iron, and the cofactor tetrahydrobioptherin (BH4). Each subunit is made up of a regulatory domain comprising an ACT domain and an N-terminal unstructured tail, a catalytic domain, and a tetramerization domain [77]. PAH is regulated by three mechanisms: (i) activation at high concentrations of the substrate Phe; (ii) inhibition by the cofactor at physiological Phe concentrations; (iii) phosphorylation at a specific serine residue (Ser16) by a cAMP-dependent kinase that activates the enzyme synergically with Phe [77]. The recently solved structure of full-length human PAH in the Phe-free form and complexed with $\mathrm{BH} 4$ has revealed the structural bases of the complex regulation of the enzyme by the cofactor and suggested a certain degree of conformational plasticity of the enzyme [116]. Moreover, it is known that PAH exists as an equilibrium between a "resting" and an "activated" state, being the first favored at basal Phe concentration $(<50 \mu \mathrm{M})$, and the second favored in the presence of higher Phe concentrations ( $\gg 50 \mu \mathrm{M}$ ). This equilibrium is essential to allow Phe degradation at potential neurotoxic concentrations, while maintaining adequate availability of Phe and tyrosine for anabolic processes at basal levels [77, 117]. Phe binds to an allosteric site formed at the interface between two ACT domains at the $N$-terminus of the protein only in the activated state [118]. Structural and biophysical studies have indicated that binding of Phe to the allosteric site stabilizes a large repositioning of regulatory domains, exposing the active site $[119,120]$. The latter movement also stabilizes the protein against denaturation and proteolytic cleavage [121, 122].

In PKU patients, accumulating Phe is transaminated to phenylpyruvate that not only accumulates at toxic concentrations, but also generates secondary metabolites such as phenyllactate and phenylacetate. The neurological symptoms of PKU are probably due to accumulating Phe that saturates the LAT- 1 transporter of neutral amino acids in the central nervous system. In addition, decreased levels of tyrosine may also play a role on disease pathogenesis because this amino acid is an important precursor of dopamine, norepinephrine, and adrenaline. PKU treatment must be initiated within the first 10 days of life to prevent any irreversible tissue damage [123]. However, no definitive treatments are currently available. A Pherestricted diet allows to prevent neurological symptoms, but strict adherence to treatment is difficult to obtain from patients [124]. Other approaches include the administration of large-neutral amino acids, to prevent excessive increase in the brain, and ERT based on the administration of the enzyme Phe ammonia lyase from Anabaena variabilis, which catabolizes Phe to transcinnamic acid and ammonia [112]. The enzyme is usually intraperitoneally administered in a PEGylated form, but the encapsulation in erythrocytes to protect from degradation and immunological reaction of pa- tients has been tested at preclinical level [125].

In the last years, numerous studies have been performed to better understand PKU pathogenesis. Among the $1000+$ of different mutations identified by genetic analysis of the patients, it has been observed that in many cases the loss of PAH enzymatic function results from single amino acid replacements that increase the tendency to misfolding, conformational destabilization and rapid degradation [68, 126, 127]. In addition, the data on the complex regulation of the enzyme, and the associated conformational changes, in particular those occurring upon the shift between the "resting" and the "activated" state, have led to a new view of PKU pathogenesis in which pathogenic mutations can affect the equilibrium between the conformers, so that the enzyme is not able to sense and respond to increased Phe concentration. The latter view point more to an inability to shift between native conformers rather than to misfolding itself as the cause of PAH functional deficit in PKU [128]. Overall, the latter results have prompted researchers to implement approaches based on small-molecules acting as PCs for PAH that could address the loss-of-function molecular phenotype and restore the Phe degradation ability.

A first approach has been the pharmacological administration of the natural cofactor $\mathrm{BH} 4$, approved by FDA and EMA and commercialized as sapropterin dihydrochloride [129, 130]. In responsive patients, $\mathrm{BH} 4$ decreases blood Phe concentration and/or increases dietary Phe tolerance [131-133]. It has been reported that a minority of PKU patients are responsive to $\mathrm{BH} 4$, and that responsiveness is usually associated with mutations giving rise to mild effects, although clear genotype/phenotype correlations have not been established. Attempts to implement personalized medicine in PKU have been made using an approach called activity landscape, which provides a link between mutations, their functional consequences on PAH activity, and the responsiveness to BH4. This approach allowed to analyze the enzyme kinetics in a wide range of substrate and cofactor concentrations, thus better dissecting the effects of each mutation, as well as predict disease severity and possible responsiveness based on the genotype [134, 135].

The understanding of structural bases of $\mathrm{BH} 4$ responsiveness is not straightforward. It is known that $\mathrm{BH} 4$ and PAH concentrations are similar in liver hepatocytes, and that the cofactor forms a dead-end complex with the enzyme at physiological Phe concentrations [136]. When blood Phe concentration increases, $\mathrm{PAH}$ is activated by allosteric Phe binding. A first hypothesis to explain responsiveness was linked to the mere kinetic role of BH4. However, only few PKU-linked variants display a low affinity for the coenzyme. Further investigations demonstrated that $\mathrm{BH} 4$ is effective in counteracting the effects of misfoldinginducing mutations, thus behaving as a PC [137]. The chaperone role of $\mathrm{BH} 4$ has been evidenced on both purified variants, where $\mathrm{BH} 4$ is able to protect $\mathrm{PAH}$ unsta- 
ble variants from thermal denaturation and their stabilizing effects propagated throughout all the protein structure, and cellular model systems, where a protection against degradation by the ubiquitin proteasome system has been shown [138, 139]. The structure of full-length PAH has revealed that $\mathrm{BH} 4$ binding to the apoenzyme causes conformational changes that propagate from the regulatory domain to the oligomerization domain and also involve the active site [116]. These changes have also explained the thermodynamic stabilization exerted by $\mathrm{BH} 4$, which results in an increased resistance to thermal stress. In addition, the changes in one monomer also influence dimerization and tetramerization.

Notwithstanding the satisfactory results obtained by $\mathrm{BH} 4$ administration, responsiveness is limited to a minority of patients, and a variable clinical outcome is observed even among responders [140]. Therefore, a search for other molecules acting as PCs has been undertaken. One of the tested possibilities has been the search for coenzyme analogues performed by virtual screening followed by in vitro and in vivo assays. This strategy allowed to identify two compounds that bind at the $\mathrm{BH} 4$ site and induce a significant stabilization of PAH against misfolding and degradation, one of which is more effective that the cofactor itself [141]. A strategy based on the identification of substrate analogs has been also undertaken. In 2008, high-throughput screening of molecules able to induce a thermal stabilization of PAH allowed to identify two hit compounds effective both in vitro and in vivo [117]. The binding at the PAH active site was also determined by crystallography, thus providing insights into the molecular mechanism explaining the chaperone effect [139]. Recently, Lopes R.R. et al. [142] applied a different strategy to target the whole PAH active site, including the binding sites for the substrate, the cofactor, and the non-heme ferric center. Through a combination of studies using purified PAH and cellular models, aiming at investigating both the direct binding of the molecules and their protective effect against enzyme denaturation/degradation, the authors were able to identify putative PCs that stabilize PAH in the active conformation. Interestingly, one of them binds a region remote from the catalytic and the allosteric sites, thus possibly representing a "second-generation" non-inhibitory PC [142]. In this regard, a strategy based on the use of small-molecules that bind PAH in a site remote from the active site has been also considered promising for mutations affecting the equilibrium among alternative PAH structures. This approach is based on the idea that any molecule able to specifically bind the "activated" conformation would rescue for the mutations effects while avoiding the risk of a constitutive activation of the enzyme which could lead to unwanted dangerous reduction in the plasmatic Phe concentration [128].

\subsection{Primary hyperoxaluria type I}

The term hyperoxaluria refers to a pathologic increase in urinary excretion of oxalate. In humans, oxalate is an end-product of metabolism, mainly produced in the liver from the catabolism of hydroxyproline and glycolate $[143,144]$. Any defect in the production or excretion of oxalate leads to its progressive accumulation in the kidneys, thus allowing the formation of the poorly soluble calcium oxalate $(\mathrm{CaOx})$ that precipitates generating kidney stones. Hyperoxalurias can be distinguished into two categories: (i) primary hyperoxalurias, rare inborn errors of glyoxylate metabolism that result in a high endogenous oxalate production. (ii) secondary hyperoxalurias, non-genetic forms of the disease caused by an increased exogenous oxalate absorption, as consequence of various alterations including intestinal inflammation, bariatric surgery, or excessive intake of oxalate precursors [145]. The three types of PH are distinguished based on the mutated gene. Among them, Primary Hyperoxaluria Type 1 (PH1, OMIM 259900) is the most frequent (about $80 \%$ of $\mathrm{PH}$ patients) and severe form [146, 147]. PH1 is due to mutations in the AGXT gene encoding liver peroxisomal alanine: glyoxylate aminotransferase (AGT), and is characterized by an autosomal recessive inheritance. The global prevalence is about 1 to 3 per million people and the incidence is approximately 1:120000 live births in Europe and North America [148, 149]. Patients affected by $\mathrm{PH} 1$ show a deposition of $\mathrm{CaOx}$ and its progressive accumulation in the kidneys eventually leading to renal failure. Upon renal failure, the excessive oxalate synthesis by the liver is compounded by the failure to remove it from the body. This results in a potentially fatal condition named systemic oxalosis, with $\mathrm{CaOx}$ to deposit into many organs and tissues [150, 151].

AGT is liver peroxisomal homodimeric enzyme belonging to the Fold Type I family of pyridoxal 5'phosphate (PLP)-dependent enzymes [152]. Each subunit is made up of an N-terminal arm wrapping over the surface of the neighboring subunit, a large domain comprising the active site, and a small C-terminal domain where the regions mediating peroxisomal targeting are located [153]. PLP is covalently bound through a Schiff base with Lys209 and interacts with the apoprotein through residues belonging to both subunits [152]. AGT is functionally involved in the metabolism of glyoxylate, and it catalyzes the transamination of L-alanine and glyoxylate into pyruvate and glycine. Although the catalytic pathway of the reaction is typical of PLP-dependent transaminases, AGT is peculiar because the equilibrium of the reaction is largely shifted toward glyoxylate-to-glycine conversion, in line with the role of the enzyme in glyoxylate detoxification [154]. This explains why in PH1 patients the deficit of AGT causes glyoxylate accumulation, thus allowing its conversion to oxalate by lactate dehydrogenase in hepatocyte cytosol [146, 155]. 
Classical treatments for $\mathrm{PH} 1$ aim at preventing kidney failure or restoring kidney function. They include a high fluid intake, the administration of crystallization inhibitors, lithotripsy, dialysis, and/or kidney transplantation procedures [147]. Only two therapeutic approaches directed to the causes of the disease are available so far: the administration of pharmacological doses of Vitamin B6 in form of pyridoxine (PN), and liver transplantation $[145,156]$. Liver transplantation is the most resolutive action to restore the total activity of AGT, but it is a very invasive procedure associated with significant potential sideeffects. On the other hand, the administration of PN, that is converted to the natural cofactor of AGT, PLP, is effective only in a small percentage (less than 30\%) of patients $[147,157]$. Very recently, a drug based on the RNA silencing technology named Lumasiran $\left(\mathrm{Oxlumo}^{\mathrm{TM}}\right.$ ) has been approved for the treatment of PH1 [158]. It is directed against the HAO1 gene encoding glycolate oxidase, and it represents a SRT approach because it counteracts the synthesis of glyoxylate. An analogous technology having as target lactate dehydrogenase (Nedosiran) is currently under clinical testing (NCT04580420 NCT03392896 NCT02795325). Although these new approaches hold promise for PH1 patients, they represent very expensive long-life treatments, whose risk/benefit ratios should be carefully evaluated by physicians. Thus, alternative approaches based on small molecules or biologic drugs are currently under investigation [159].

Among the more than 200 PH1-associated mutations identified so far, missense mutations are wellrepresented [160]. It has been widely demonstrated that most pathogenic amino acid substitutions do not affect the intrinsic catalytic activity of the protein, but rather alter its folding pathway. Thus, misfolding has emerged as one of the main mechanisms underlying the AGT loss-offunction in PH1. The downstream effects of AGT misfolding are various and include a reduced stability of the dimeric unit, a higher susceptibility to proteolytic degradation, an increased aggregation propensity, or mistargeting to mitochondria where AGT is functionally ineffective [161, 162]. The latter is a pathogenic mechanism peculiar of PH1 in which a polymorphism normally present in $20 \%$ of Caucasian population generates a weak mitochondrial targeting sequence, whose effects become evident only if pathogenic mutations interfering with folding are concomitantly present [163-165].

On the basis of these knowledge, the possibility to develop a non-invasive treatment approach for PH1 based on the use of PCs has been considered. First, it must be underlined that a chaperone action of the PLP coenzyme on AGT has been demonstrated for most variants showing folding defects $[151,161,166]$. PLP is bound at the interface between the two subunits of the AGT dimer. The chaperone effect is mediated by a variety of mechanisms including (i) the promotion of dimerization [167, 168]; (ii) an im- proved efficiency of the folding process, with also includes the correct targeting [163, 166]; (iii) an overall stabilization of AGT native structure against electrostatically-driven aggregation [169]. Based on the chaperone role of PLP, which allows to rationalize the effects of $\mathrm{PN}$ administration to $\mathrm{PH} 1$ patients, cellular studies on other B6 vitamers have been performed. They showed that other vitamers can be more effective than PN in rescuing folding-defective variants. In fact, in the presence of excess PN, pyridoxine phosphate accumulates in the cytosol and competes with PLP leading to the formation of an inactive complex. This explains why AGT inhibition is observed upon PN administration to cell expressing the wild-type form [170]. Recent data based on a combined molecular/cellular study on variants bearing mutations of interface residues have allowed to establish that (i) the higher is the structural perturbation caused by a mutation, the lower is responsiveness to PN [166], and that (ii) the co-inheritance of the minor allele polymorphism can not only influence the severity of the effect of PH1-associated mutations, but also their responsiveness to PN [165].

Another molecule that acts as PC for AGT is aminooxyacetic acid. It binds the active site of AGT and behaves as competitive tight-binding inhibitor that forms an oxime with the carbonylic group of PLP. Although data in cellular models indicate that aminooxyacetic acid behaves as a PC for AGT pathogenic variants showing folding defects, promoting the achievement of their correctly folded structure, it is not specific, being able to interact with many PLP-enzymes and free PLP. For these reasons, a small screening campaign based on the aminooxyacetic acid scaffold has been undertaken and led to the identification of hit-compounds that are active on some of the most frequent AGT variants as promising candidates to be developed for the treatment of PH1 [171].

Recently, cycloserine enantiomers have been also considered as a possible AGT inhibitors suitable as PC. Lcycloserine is a synthetic compound used as regulator of lipid metabolism in vitro, while D-cycloserine, the natural enantiomer, is used as second-line approach in the treatment of tuberculosis [172]. Both compounds behave as irreversible inhibitors of several PLP-dependent transaminases, racemases and decarboxylases [173]. A study on the interaction of cycloserine with AGT has demonstrated that both enantiomers are able to bind the AGT active site with high affinity and inhibit transaminase activity in a reversible competitive fashion although with different mechanisms. In fact, while the L-enantiomer is a classical competitive inhibitor, the D-enantiomer is a time-dependent inhibitor. Interestingly, only D-cycloserine displays a PC activity on a mutant form of AGT prone to misfolding. The latter data have suggested that a new line of intervention against PH1 could be also based on a drug repositioning approach [174].

As already mentioned, one of the downstream effects of AGT misfolding in PH1 is mitochondrial mistargeting. A solid platform based on the use of Chinese Ham- 
ster Ovary cells expressing the most frequent mistargeted variant G170R, has been implemented to identify small molecules able to promote folding and reroute the protein to peroxisomes [175]. The application to the screening of libraries of drugs accepted by FDA and/or EMA, led to the selection of three active drugs belonging to the family of ionophores, which showed EC50 in the micromolar range [176].

\section{Conclusions}

The use of PCs represents a promising pharmacological strategy to treat rare disorders associated with protein misfolding. The administration of coenzymes, such as $\mathrm{BH} 4$ in $\mathrm{PKU}$ or $\mathrm{PN}$ in $\mathrm{PH} 1$, represents a safe and cost-effective approach that is usually attempted in all patients bearing missense mutations. However, the efficacy is limited to a minority of patients, and no clear genotype/phenotype correlations have been established, possibly due to the influence of modifier genes and/or environmental factors. Substrate analogues have also represented a cheap solution for some disorders, although their efficacy in vitro does not always translate into efficacy in clinical trials. The latter finding can be partly ascribed to the fact that most PCs are also inhibitors of the target enzyme, and it is very difficult to balance the inhibitory and the chaperone effects. Therefore, second generation PCs able to bind enzyme clefts different from the active site are considered a good solution to improve folding efficiency of conformational variants while avoiding the inhibition of catalytic activity.

\section{Author contributions}

BC conceived the content of the review, supervised the work, participated in the original draft of the manuscript and edited the final version; GP, SG, LG, EML and IL participated in the original draft of the manuscript.

\section{Ethics approval and consent to participate}

Not applicable.

\section{Acknowledgment}

Thanks to all the peer reviewers for their opinions and suggestions.

\section{Funding}

This research was funded by Oxalosis and Hyperoxaluria Foundation, grant number OHF2017 to B.C.

\section{Conflict of interest}

The authors declare no conflict of interest.

\section{References}

[1] Nassar R, Dignon GL, Razban RM, Dill KA. The Protein Folding Problem: the Role of Theory. Journal of Molecular Biology. 2021; 433: 167126.

[2] Anfinsen CB. Principles that govern the folding of protein chains. Science. 1973; 181: 223-230.

[3] Hingorani KS, Gierasch LM. Comparing protein folding in vitro and in vivo: foldability meets the fitness challenge. Current Opinion in Structural Biology. 2014; 24: 81-90.

[4] Mallamace F, Corsaro C, Mallamace D, Vasi S, Vasi C, Baglioni $\mathrm{P}$, et al. Energy landscape in protein folding and unfolding. Proceedings of the National Academy of Sciences of the United States of America. 2016; 113: 3159-3163.

[5] Stollar EJ, Smith DP. Uncovering protein structure. Essays in Biochemistry. 2020; 64: 649-680.

[6] Muñoz V, Cerminara M. When fast is better: protein folding fundamentals and mechanisms from ultrafast approaches. Biochemical Journal. 2016; 473: 2545-2559.

[7] Dill KA, Chan HS. From Levinthal to pathways to funnels. Nature Structural Biology. 1997; 4: 10-19.

[8] Onuchic JN, Socci ND, Luthey-Schulten Z, Wolynes PG. Protein folding funnels: the nature of the transition state ensemble. Folding \& Design. 1996; 1: 441-450.

[9] Ivankov DN, Finkelstein A V. Solution of Levinthal's Paradox and a Physical Theory of Protein Folding Times. Biomolecules. 2020; 10: 250 .

[10] Malhotra P, Udgaonkar JB. How cooperative are protein folding and unfolding transitions? Protein Science. 2016; 25: 19241941.

[11] Englander SW, Mayne L. The nature of protein folding pathways. Proceedings of the National Academy of Sciences of the United States of America. 2014; 111: 15873-15880.

[12] Mannini B, Chiti F. Chaperones as Suppressors of Protein Misfolded Oligomer Toxicity. Frontiers in Molecular Neuroscience. 2017; 10: 98.

[13] Chong S, Im H, Ham S. Explicit Characterization of the Free Energy Landscape of pKID-KIX Coupled Folding and Binding. American Chemical Society Central Science. 2019; 5: 1342 1351.

[14] Kuwajima K. The Molten Globule, and Two-State vs. Non-TwoState Folding of Globular Proteins. Biomolecules. 2020; 10: 407.

[15] Wolynes P, Luthey-Schulten Z, Onuchic J. Fast-folding experiments and the topography of protein folding energy landscapes. Journal of Chemical Biology. 1996; 3: 425-432.

[16] Dobson CM. Protein folding and misfolding. Nature. 2003; 426: 884-890.

[17] Wang J, Oliveira RJ, Chu X, Whitford PC, Chahine J, Han W, et al. Topography of funneled landscapes determines the thermodynamics and kinetics of protein folding. Proceedings of the National Academy of Sciences of the United States of America. 2012; 109: 15763-15768.

[18] Bemporad F, Chiti F. “Native-like aggregation” of the acylphosphatase from Sulfolobus solfataricus and its biological implications. Federation of European Biochemical Societies. 2009; 583: 2630-2638.

[19] Uversky VN. Protein intrinsic disorder and structure-function continuum. Progress in Molecular Biology and Translational Science. 2019; 8: 1-17.

[20] Gianni S, Freiberger MI, Jemth P, Ferreiro DU, Wolynes PG, Fuxreiter M. Fuzziness and Frustration in the Energy Landscape of Protein Folding, Function, and Assembly. Accounts of Chemical Research. 2021; 54: 1251-1259.

[21] Zhang Z, Witham S, Alexov E. On the role of electrostatics in protein-protein interactions. Physical Biology. 2011; 8: 035001.

[22] Chiti F, Dobson CM. Protein Misfolding, Amyloid Formation, and Human Disease: a Summary of Progress over the last Decade. Annual Review of Biochemistry. 2017; 86: 27-68. 
[23] Uyar B, Weatheritt RJ, Dinkel H, Davey NE, Gibson TJ. Proteome-wide analysis of human disease mutations in short linear motifs: neglected players in cancer? Molecular BioSystems. 2014; 10: 2626-2642.

[24] van der Lee R, Buljan M, Lang B, Weatheritt RJ, Daughdrill GW, Dunker AK, et al. Classification of intrinsically disordered regions and proteins. Chemical Reviews. 2014; 114: 65896631.

[25] Singh N, Bhalla N. Moonlighting Proteins. Annual Review of Genetics. 2020; 54: 265-285.

[26] Li W, Kinch LN, Karplus PA, Grishin NV. ChSeq: a database of chameleon sequences. Protein Science. 2015; 24: 1075-1086.

[27] Jaffe EK. Morpheeins-a new structural paradigm for allosteric regulation. Trends in Biochemical Sciences. 2005; 30: 490-497.

[28] Dishman AF, Volkman BF. Unfolding the Mysteries of Protein Metamorphosis. American Chemical Society Chemical Biology. 2018; 13: 1438-1446.

[29] Liu H, Jeffery CJ. Moonlighting Proteins in the Fuzzy Logic of Cellular Metabolism. Molecules. 2020; 25: 3440.

[30] McDonald S, Murphy T, Imberti S, Warr GG, Atkin R. Amphiphilically Nanostructured Deep Eutectic Solvents. The Journal of Physical Chemistry Letters. 2018; 9: 3922-3927.

[31] Balchin D, Hayer-Hartl M, Hartl FU. In vivo aspects of protein folding and quality control. Science. 2016; 353: aac4354.

[32] Weis BL, Schleiff E, Zerges W. Protein targeting to subcellular organelles via MRNA localization. Biochimica et Biophysica Acta. 2013; 1833: 260-273.

[33] Cheung MS, Arcus V. Editorial overview: Protein folding and binding: from protein folding in vitro to hierarchical assembly in vivo. Current Opinion in Structural Biology. 2021; 66: vi-vii.

[34] Gámez A, Yuste-Checa P, Brasil S, Briso-Montiano Á, Desviat LR, Ugarte M, et al. Protein misfolding diseases: Prospects of pharmacological treatment. Clinical Genetics. 2018; 93: 450458.

[35] Sun Z, Brodsky JL. Protein quality control in the secretory pathway. Journal of Cell Biology. 2019; 218: 3171-3187.

[36] Labbadia J, Morimoto RI. The biology of proteostasis in aging and disease. Annual Review of Biochemistry. 2015; 84: 435464

[37] Dong Z, Cui H. The Autophagy-Lysosomal Pathways and Their Emerging Roles in Modulating Proteostasis in Tumors. Cells. 2018; 8: 4.

[38] Barrio R, Sutherland JD. Proteostasis: the network behind the networks. Seminars in Cell \& Developmental Biology. 2019; 93: 97-99.

[39] Dobson CM. Principles of protein folding, misfolding and aggregation. Seminars in Cell \& Developmental Biology. 2004; 15: 3-16.

[40] Rodríguez-Bolaños M, Miranda-Astudillo H, Pérez-Castañeda E, González-Halphen D, Perez-Montfort R. Native aggregation is a common feature among triosephosphate isomerases of different species. Scientific Reports. 2020; 10: 1338.

[41] Bemporad F, De Simone A, Chiti F, Dobson C. Characterizing Intermolecular Interactions that Initiate Native-Like Protein Aggregation. Biophysical Journal. 2012; 102: 2595-2604.

[42] Jeffery CJ. Protein moonlighting: what is it, and why is it important? Philosophical Transactions of the Royal Society B: Biological Sciences. 2018; 373: 20160523.

[43] Jaffe EK, Stith L. ALAD porphyria is a conformational disease. American Journal of Human Genetics. 2007; 80: 329-337.

[44] Gregersen N, Bross P, Vang S, Christensen JH. Protein misfolding and human disease. Annual Review of Genomics and Human Genetics. 2006; 7: 103-124.

[45] Yadav K, Yadav A, Vashistha P, Pandey VP, Dwivedi UN. Protein Misfolding Diseases and Therapeutic Approaches. Current Protein \& Peptide Science. 2019; 20: 1226-1245.

[46] Winklhofer KF, Tatzelt J, Haass C. The two faces of protein misfolding: gain- and loss-of-function in neurodegenerative diseases. The European Molecular Biology Organization. 2008; 27: 336-349.
[47] Sweeney P, Park H, Baumann M, Dunlop J, Frydman J, Kopito R, et al. Protein misfolding in neurodegenerative diseases: implications and strategies. Translational Neurodegeneration. 2017; 6: 6 .

[48] Klaips CL, Jayaraj GG, Hartl FU. Pathways of cellular proteostasis in aging and disease. The Journal of Cell Biology. 2018; 217: 51-63.

[49] Haendel M, Vasilevsky N, Unni D, Bologa C, Harris N, Rehm H, et al. How many rare diseases are there? Nature Reviews Drug Discovery. 2020; 19: 77-78.

[50] Turner TN, Douville C, Kim D, Stenson PD, Cooper DN, Chakravarti A, et al. Proteins linked to autosomal dominant and autosomal recessive disorders harbor characteristic rare missense mutation distribution patterns. Human Molecular Genetics. 2015; 24: 5995-6002.

[51] Jung S, Lee S, Kim S, Nam H. Identification of genomic features in the classification of loss- and gain-of-function mutation. BMC Medical Informatics and Decision Making. 2015; 15: S6.

[52] Bross P, Corydon TJ, Andresen BS, Jørgensen MM, Bolund L, Gregersen N. Protein misfolding and degradation in genetic diseases. Human Mutation. 1999; 14: 186-198.

[53] Chaudhuri TK, Paul S. Protein-misfolding diseases and chaperone-based therapeutic approaches. The Federation of $\mathrm{Eu}-$ ropean Biochemical Societies Journal. 2006; 273: 1331-1349.

[54] Liguori L, Monticelli M, Allocca $M$ et al. Pharmacological Chaperones: A Therapeutic Approach for Diseases Caused by Destabilizing Missense Mutations. International Journal of Molecular Sciences. 2020; 21: 489.

[55] Naik S, Zhang N, Gao P, Fisher MT. On the design of broad based screening assays to identify potential pharmacological chaperones of protein misfolding diseases. Current Topics in Medicinal Chemistry. 2012; 12: 2504-2522.

[56] Fan JQ, Ishii S, Asano N, Suzuki Y. Accelerated transport and maturation of lysosomal alpha-galactosidase a in Fabry lymphoblasts by an enzyme inhibitor. Nature Medicine. 1999; 5 : 112-115.

[57] Morello JP, Salahpour A, Laperrière A, Bernier V, Arthus MF, Lonergan $\mathrm{M}$, et al. Pharmacological chaperones rescue cellsurface expression and function of misfolded V2 vasopressin receptor mutants. The Journal of Clinical Investigation. 2000; 105: 887-895.

[58] Shin S, Murray GJ, Kluepfel-Stahl S, Cooney AM, Quirk JM, Schiffmann R, et al. Screening for pharmacological chaperones in Fabry disease. Biochemical and Biophysical Research Communications. 2007; 359: 168-173.

[59] Parenti G, Andria G, Valenzano KJ. Pharmacological Chaperone Therapy: Preclinical Development, Clinical Translation, and Prospects for the Treatment of Lysosomal Storage Disorders. Molecular Therapy. 2015; 23: 1138-1148.

[60] Tao Y, Conn PM. Chaperoning G protein-coupled receptors: from cell biology to therapeutics. Endocrine Reviews. 2014; 35 602-647.

[61] Papp E, Csermely P. Chemical chaperones: mechanisms of action and potential use. Handbook of Experimental Pharmacology. 2006; 172: 405-416.

[62] Ringe D, Petsko GA. What are pharmacological chaperones and why are they interesting? Journal of Biology. 2009; 8: 80.

[63] Convertino M, Das J, Dokholyan NV. Pharmacological Chaperones: Design and Development of New Therapeutic Strategies for the Treatment of Conformational Diseases. American Chemical Society Chemical Biology. 2016; 11: 1471-1489.

[64] Leandro P, Gomes CM. Protein misfolding in conformational disorders: rescue of folding defects and chemical chaperoning. Mini Reviews in Medicinal Chemistry. 2008; 8: 901-911.

[65] Wang Y, Di X, Mu T. Using pharmacological chaperones to restore proteostasis. Pharmacological Research. 2014; 83: 3-9.

[66] Gupta AN, Neupane K, Rezajooei N, Cortez LM, Sim VL, Woodside MT. Pharmacological chaperone reshapes the energy landscape for folding and aggregation of the prion protein. Na- 
ture Communications. 2016; 7: 12058.

[67] Jiang Y, Kalodimos CG. Confirmation for conformational selection. ELife. 2018; 7: e34923.

[68] Aymami J, Barril X, Rodríguez-Pascau L, Martinell M. Pharmacological chaperones for enzyme enhancement therapy in genetic diseases. Pharmaceutical Patent Analyst. 2013; 2: 109124

[69] Leidenheimer NJ. Cognate Ligand Chaperoning: a Novel Mechanism for the Post-translational Regulation of Neurotransmitter Receptor Biogenesis. Frontiers in Cellular Neuroscience. 2017; 11: 245.

[70] Gomes CM. Protein misfolding in disease and small molecule therapies. Current Topics in Medicinal Chemistry. 2012; 12: 2460-2469.

[71] Abramov D, Guiberson NGL, Daab A, Na Y, Petsko GA, Sharma M, et al. Targeted stabilization of Munc18-1 function via pharmacological chaperones. The European Molecular Biology Organization Molecular Medicine. 2021; 13: e12354.

[72] Tao Y, Conn PM. Pharmacoperones as Novel Therapeutics for Diverse Protein Conformational Diseases. Physiological Reviews. 2018; 98: 697-725.

[73] Marinko JT, Huang H, Penn WD, Capra JA, Schlebach JP, Sanders CR. Folding and Misfolding of Human Membrane Proteins in Health and Disease: from Single Molecules to Cellular Proteostasis. Chemical Reviews. 2019; 119: 5537-5606.

[74] Muntau AC, Leandro J, Staudigl M, Mayer F, Gersting SW. Innovative strategies to treat protein misfolding in inborn errors of metabolism: pharmacological chaperones and proteostasis regulators. Journal of Inherited Metabolic Disease. 2014; 37: 505523.

[75] Cellini B, Montioli R, Oppici E, Astegno A, Voltattorni CB. The chaperone role of the pyridoxal 5'-phosphate and its implications for rare diseases involving B6-dependent enzymes. Clinical Biochemistry. 2014; 47: 158-165.

[76] Chen C, Park C. Chaperone action of a cofactor in protein folding. Protein Science. 2020; 29: 1667-1678.

[77] Flydal MI, Martinez A. Phenylalanine hydroxylase: function, structure, and regulation. International Union of Biochemistry and Molecular Biology Life. 2013; 65: 341-349.

[78] Valenzano KJ, Khanna R, Powe AC, Boyd R, Lee G, Flanagan $\mathrm{JJ}$, et al. Identification and characterization of pharmacological chaperones to correct enzyme deficiencies in lysosomal storage disorders. Assay and Drug Development Technologies. 2011; 9: 213-235.

[79] Marques ARA, Saftig P. Lysosomal storage disorders - challenges, concepts and avenues for therapy: beyond rare diseases. Journal of Cell Science. 2019; 132: jcs221739.

[80] Suzuki Y. Chaperone therapy for molecular pathology in lysosomal diseases. Brain and Development. 2021; 43: 45-54.

[81] Sun A. Lysosomal storage disease overview. Annals of Translational Medicine. 2018; 6: 476.

[82] Wang RY, Bodamer OA, Watson MS, Wilcox WR. Lysosomal storage diseases: Diagnostic confirmation and management of presymptomatic individuals. Genetics in Medicine. 2011; 13: 457-484.

[83] Pereira DM, Valentão P, Andrade PB. Tuning protein folding in lysosomal storage diseases: the chemistry behind pharmacological chaperones. Chemical Science. 2018; 9: 1740-1752.

[84] Baris HN, Cohen IJ, Mistry PK. Gaucher disease: the metabolic defect, pathophysiology, phenotypes and natural history. Pediatric Endocrinology Reviews. 2014; 12: 72-81.

[85] Mignot C, Gelot A, De Villemeur TB. Gaucher disease. Handbook of Clinical Neurology. 2013; 113: 1709-1715.

[86] Stirnemann J, Belmatoug N, Camou F, Serratrice C, Froissart R, Caillaud C, et al. A Review of Gaucher Disease Pathophysiology, Clinical Presentation and Treatments. International Journal of Molecular Sciences. 2017; 18: 441.

[87] Sato C, Morgan A, Lang AE, Salehi-Rad S, Kawarai T, Meng $\mathrm{Y}$, et al. Analysis of the glucocerebrosidase gene in Parkinson's disease. Movement Disorders. 2005; 20: 367-370.
[88] Holick MF. The photobiology of vitamin D and its consequences for humans. Annals of the New York Academy of Sciences. 1985; 453: 1-13.

[89] Schapira AHV. Glucocerebrosidase and Parkinson disease: Recent advances. Molecular and Cellular Neurosciences. 2015; 66 : 37-42.

[90] Belmatoug N, Di Rocco M, Fraga C, Giraldo P, Hughes D, Lukina $\mathrm{E}$, et al. Management and monitoring recommendations for the use of eliglustat in adults with type 1 Gaucher disease in $\mathrm{Eu}$ rope. European Journal of Internal Medicine. 2017; 37: 25-32.

[91] Ron I, Horowitz M. ER retention and degradation as the molecular basis underlying Gaucher disease heterogeneity. Human Molecular Genetics. 2005; 14: 2387-2398.

[92] Sawkar AR, Cheng W, Beutler E, Wong C, Balch WE, Kelly JW. Chemical chaperones increase the cellular activity of N370S beta -glucosidase: a therapeutic strategy for Gaucher disease. Proceedings of the National Academy of Sciences of the United States of America. 2002; 99: 15428-15433.

[93] Braunstein H, Maor G, Chicco G, Filocamo M, Zimran A, Horowitz M. UPR activation and CHOP mediated induction of GBA1 transcription in Gaucher disease. Blood Cells, Molecules \& Diseases. 2018; 68: 21-29.

[94] Suzuki Y. Chaperone therapy update: Fabry disease, GM1gangliosidosis and Gaucher disease. Brain \& Development. 2013; 35: 515-523.

[95] Matassini C, Warren J, Wang B, Goti A, Cardona F, Morrone A, et al. Imino- and Azasugar Protonation inside Human Acid $\beta$ Glucosidase, the Enzyme that is Defective in Gaucher Disease. Angewandte Chemie International Edition. 2020; 59: 10466 10469.

[96] Luan Z, Higaki K, Aguilar-Moncayo M, Ninomiya H, Ohno K, GarcÃa-Moreno MI, et al. Chaperone Activity of Bicyclic Nojirimycin Analogues for Gaucher Mutations in Comparison withN(n-nonyl) Deoxynojirimycin. ChemBioChem. 2009; 10: 2780 2792.

[97] Mena-Barragán T, García-Moreno MI, Nanba E, Higaki K, Concia AL, Clapés $\mathrm{P}$, et al. Inhibitor versus chaperone behaviour of d-fagomine, $\mathrm{DAB}$ and $\mathrm{LAB} \operatorname{sp}(2)$-iminosugar conjugates against glycosidases: a structure-activity relationship study in Gaucher fibroblasts. European Journal of Medicinal Chemistry. 2016; 121: 880-891.

[98] Chang H, Asano N, Ishii S, Ichikawa Y, Fan J. Hydrophilic iminosugar active-site-specific chaperones increase residual glucocerebrosidase activity in fibroblasts from Gaucher patients. The Federation of European Biochemical Societiesis Journal. 2006; 273: 4082-4092.

[99] Khanna R, Benjamin ER, Pellegrino L, Schilling A, Rigat BA, Soska $\mathrm{R}$, et al. The pharmacological chaperone isofagomine increases the activity of the Gaucher disease L444P mutant form of beta-glucosidase. The Federation of European Biochemical Societiesis Journal. 2010; 277: 1618-1638.

[100] Clemente F, Matassini C, Goti A, Morrone A, Paoli P, Cardona F. Stereoselective Synthesis of C-2 Alkylated Trihydroxypiperidines: Novel Pharmacological Chaperones for Gaucher Disease. American Chemical Society Medicinal Chemistry Letters. 2019; 10: 621-626.

[101] Clemente F, Matassini C, Faggi C, Giachetti S, Cresti C, Morrone A, et al. Glucocerebrosidase (GCase) activity modulation by 2-alkyl trihydroxypiperidines: Inhibition and pharmacological chaperoning. Bioorganic Chemistry. 2020; 98: 103740.

[102] Maegawa GHB, Tropak MB, Buttner JD, Rigat BA, Fuller M, Pandit D, et al. Identification and Characterization of Ambroxol as an Enzyme Enhancement Agent for Gaucher Disease. Journal of Biological Chemistry. 2009; 284: 23502-23516.

[103] Migdalska-Richards A, Ko WKD, Li Q, Bezard E, Schapira AHV. Oral ambroxol increases brain glucocerebrosidase activity in a nonhuman primate. Synapse. 2017; 71: e21967.

[104] Kopytova AE, Rychkov GN, Nikolaev MA, Baydakova GV Cheblokov AA, Senkevich KA, et al. Ambroxol increases glu- 
cocerebrosidase (GCase) activity and restores GCase translocation in primary patient-derived macrophages in Gaucher disease and Parkinsonism. Parkinsonism \& Related Disorders. 2021; 84: 112-121.

[105] Zimran A, Altarescu G, Elstein D. Pilot study using ambroxol as a pharmacological chaperone in type 1 Gaucher disease. Blood Cells, Molecules \& Diseases. 2013; 50: 134-137.

[106] Istaiti M, Revel-Vilk S, Becker-Cohen $\mathbf{M}$ et al. Upgrading the evidence for the use of ambroxol in Gaucher disease and GBA related Parkinson: Investigator initiated registry based on real life data. American journal of hematology. 2021; 96: 545-551.

[107] Zheng J, Chen L, Skinner OS et al. $\beta$-Glucocerebrosidase Modulators Promote Dimerization of $\beta$-Glucocerebrosidase and Reveal an Allosteric Binding Site. The Journal of the American Chemical Society. 2018; 140: 5914-5924.

[108] Patnaik S, Zheng W, Choi JH, Motabar O, Southall N, Westbroek W, et al. Discovery, structure-activity relationship, and biological evaluation of noninhibitory small molecule chaperones of glucocerebrosidase. Journal of Medicinal Chemistry. 2012; 55: $5734-5748$

[109] Goldin E, Zheng W, Motabar O, Southall N, Choi JH, Marugan $\mathrm{J}$, et al. High throughput screening for small molecule therapy for Gaucher disease using patient tissue as the source of mutant glucocerebrosidase. Public Library of Science One. 2012; 7: e29861.

[110] Castellan T, Garcia V, Rodriguez F, Fabing I, Shchukin Y, Tran $\mathrm{ML}$, et al. Concise asymmetric synthesis of new enantiomeric Calkyl pyrrolidines acting as pharmacological chaperones against Gaucher disease. Organic \& Biomolecular Chemistry. 2020; 18: 7852-7861

[111] Han T-U, Sam R, Sidransky E. Small Molecule Chaperones for the Treatment of Gaucher Disease and GBA1-Associated Parkinson Disease. Frontiers in Cell and Developmental Biology. 2020; 8: 271.

[112] Blau N, van Spronsen FJ, Levy HL. Phenylketonuria. The Lancet. 2010; 376: 1417-1427.

[113] Porta F, Giorda S, Ponzone A, Spada M. Tyrosine metabolism in health and disease: slow-release amino acids therapy improves tyrosine homeostasis in phenylketonuria. Journal of Pediatric Endocrinology and Metabolism. 2020; 33: 1519-1523.

[114] Strisciuglio P, Concolino D. New Strategies for the Treatment of Phenylketonuria (PKU). Metabolites. 2014; 4: 1007-1017.

[115] Sumaily KM, Mujamammi AH. Phenylketonuria: a new look at an old topic, advances in laboratory diagnosis, and therapeutic strategies. International Journal of Health Sciences. 2019; 11: 63-70.

[116] Flydal MI, Alcorlo-Pagés M, Johannessen FG, MartínezCaballero S, Skjærven L, Fernandez-Leiro R, et al. Structure of full-length human phenylalanine hydroxylase in complex with tetrahydrobiopterin. Proceedings of the National Academy of Sciences. 2019; 116: 11229-11234.

[117] Pey AL, Ying M, Cremades N, Velazquez-Campoy A, Scherer $\mathrm{T}$, Thöny $\mathrm{B}$, et al. Identification of pharmacological chaperones as potential therapeutic agents to treat phenylketonuria. The Journal of Clinical Investigation. 2008; 118: 2858-2867.

[118] Patel D, Kopec J, Fitzpatrick F, McCorvie TJ, Yue WW. Structural basis for ligand-dependent dimerization of phenylalanine hydroxylase regulatory domain. Scientific Reports. 2016; 6: 23748.

[119] Konovalov KA, Wang W, Huang X. Conformational selection turns on phenylalanine hydroxylase. Journal of Biological Chemistry. 2018; 293: 19544-19545.

[120] Ge Y, Borne E, Stewart S, Hansen MR, Arturo EC, Jaffe EK, et al. Simulations of the regulatory ACT domain of human phenylalanine hydroxylase (PAH) unveil its mechanism of phenylalanine binding. Journal of Biological Chemistry. 2018; 293: 19532-19543.

[121] Tomé CS, Lopes RR, Sousa PMF, Amaro MP, Leandro J, Mertens HDT, et al. Structure of full-length wild-type human phenylalanine hydroxylase by small angle X-ray scattering re- veals substrate-induced conformational stability. Scientific Reports. 2019; 9: 13615 .

[122] Arturo EC, Gupta K, Hansen MR, Borne E, Jaffe EK. Biophysical characterization of full-length human phenylalanine hydroxylase provides a deeper understanding of its quaternary structure equilibrium. Journal of Biological Chemistry. 2019; 294 10131-10145.

[123] van Wegberg AMJ, MacDonald A, Ahring K, BélangerQuintana A, Blau N, Bosch AM, et al. The complete European guidelines on phenylketonuria: diagnosis and treatment. Orphanet Journal of Rare Diseases. 2017; 12: 162.

[124] Stone WL, Basit H, Los E. Phenylketonuria. StatPearls. 2021. (in press)

[125] Rossi L, Pierigè F, Carducci C, Gabucci C, Pascucci T, Canonico B, et al. Erythrocyte-mediated delivery of phenylalanine ammonia lyase for the treatment of phenylketonuria in BTBRPah(enu2) mice. Journal of Controlled Release. 2014; 194: $37-$ 44.

[126] Underhaug J, Aubi O, Martinez A. Phenylalanine hydroxylase misfolding and pharmacological chaperones. Current Topics in Medicinal Chemistry. 2012; 12: 2534-2545.

[127] Eichinger A, Danecka MK, Möglich T, Borsch J, Woidy M, Büttner L, et al. Secondary BH4 deficiency links protein homeostasis to regulation of phenylalanine metabolism. Human Molecular Genetics. 2018; 27: 1732-1742.

[128] Jaffe EK. New protein structures provide an updated understanding of phenylketonuria. Molecular Genetics and Metabolism. 2017; 121: 289-296.

[129] Blau N, Hennermann JB, Langenbeck U, Lichter-Konecki U. Diagnosis, classification, and genetics of phenylketonuria and tetrahydrobiopterin (BH4) deficiencies. Molecular Genetics and Metabolism. 2011; 104: S2-S9.

[130] Levy HL, Milanowski A, Chakrapani A, Cleary M, Lee P, Trefz FK, et al. Efficacy of sapropterin dihydrochloride (tetrahydrobiopterin, 6R-BH4) for reduction of phenylalanine concentration in patients with phenylketonuria: a phase III randomised placebo-controlled study. Lancet. 2007; 370: 504-510.

[131] Anjema K, van Rijn M, Hofstede FC, Bosch AM, Hollak CEM, Rubio-Gozalbo E, et al. Tetrahydrobiopterin responsiveness in phenylketonuria: prediction with the 48-hour loading test and genotype. Orphanet Journal of Rare Diseases. 2013; 8: 103.

[132] Muntau AC, Burlina A, Eyskens F, Freisinger P, De Laet C, Leuzzi V, et al. Efficacy, safety and population pharmacokinetics of sapropterin in PKU patients $<4$ years: results from the SPARK open-label, multicentre, randomized phase IIIb trial. Orphanet Journal of Rare Diseases. 2017; 12: 47.

[133] Keil S, Anjema K, van Spronsen FJ, Lambruschini N, Burlina A, Bélanger-Quintana A, et al. Long-term follow-up and outcome of phenylketonuria patients on sapropterin: a retrospective study. Pediatrics. 2013; 131: e1881-e1888.

[134] Staudigl M, Gersting SW, Danecka MK, Messing DD, Woidy $\mathrm{M}$, Pinkas $\mathrm{D}$, et al. The interplay between genotype, metabolic state and cofactor treatment governs phenylalanine hydroxylase function and drug response. Human Molecular Genetics. 2011; 20: 2628-2641.

[135] Danecka MK, Woidy M, Zschocke J, Feillet F, Muntau AC, Gersting SW. Mapping the functional landscape of frequent phenylalanine hydroxylase (PAH) genotypes promotes personalised medicine in phenylketonuria. Journal of Medical Genetics. 2015; 52: 175-185.

[136] Mitnaul LJ, Shiman R. Coordinate regulation of tetrahydrobiopterin turnover and phenylalanine hydroxylase activity in rat liver cells. Proceedings of the National Academy of Sciences of the United States of America. 1995; 92: 885-889.

[137] Pey AL, Pérez B, Desviat LR, Martínez MA, Aguado C, Erlandsen $\mathrm{H}$, et al. Mechanisms underlying responsiveness to tetrahydrobiopterin in mild phenylketonuria mutations. Human Mutation. 2004; 24: 388-399.

[138] Pey AL. Protein homeostasis disorders of key enzymes of 
amino acids metabolism: mutation-induced protein kinetic destabilization and new therapeutic strategies. Amino Acids. 2013; 45: 1331-1341.

[139] Torreblanca R, Lira-Navarrete E, Sancho J, Hurtado-Guerrero R. Structural and mechanistic basis of the interaction between a pharmacological chaperone and human phenylalanine hydroxylase. Chembiochem. 2012; 13: 1266-69.

[140] Bélanger-Quintana A, Burlina A, Harding CO, Muntau AC. Up to date knowledge on different treatment strategies for phenylketonuria. Molecular Genetics and Metabolism. 2011; 104: S19_ 25.

[141] Santos-Sierra S, Kirchmair J, Perna AM, Reiss D, Kemter K, Röschinger W, et al. Novel pharmacological chaperones that correct phenylketonuria in mice. Human Molecular Genetics. 2012; 21: 1877-1887.

[142] Lopes RR, Tomé CS, Russo R et al. Modulation of Human Phenylalanine Hydroxylase by 3-Hydroxyquinolin-2(1H)-One Derivatives. Biomolecules. 2021; 11: 462.

[143] Bhasin B, Ürekli HM, Atta MG. Primary and secondary hyperoxaluria: Understanding the enigma. World Journal of Nephrology. 2015; 4: 235-244.

[144] Huang Y, Zhang Y, Chi Z, Huang R, Huang H, Liu G, et al. The Handling of Oxalate in the Body and the Origin of Oxalate in Calcium Oxalate Stones. Urologia Internationalis. 2020; 104: 167-176.

[145] Shah A, Leslie SW, Ramakrishnan S. Hyperoxaluria. StatPearls. Treasure Island (FL): StatPearls Publishing. 2021. (in press)

[146] Danpure CJ, Jennings PR. Peroxisomal alanine:glyoxylate aminotransferase deficiency in primary hyperoxaluria type i. The Federation of European Biochemical Societies Letters. 1986; 201: 20-24.

[147] Hoppe B, Beck BB, Milliner DS. The primary hyperoxalurias. Kidney International. 2009; 75: 1264-1271.

[148] Harambat J, Fargue S, Bacchetta J, Acquaviva C, Cochat P. Primary hyperoxaluria. International Journal of Nephrology. 2011; 2011: 864580.

[149] Halbritter J. Genetics of kidney stone disease-Polygenic meets monogenic. NéPhrologie \& ThéRapeutique. 2021; 17: S88-S94.

[150] Beck BB, Hoyer-Kuhn H, Göbel H, Habbig S, Hoppe B. Hyperoxaluria and systemic oxalosis: an update on current therapy and future directions. Expert Opinion on Investigational Drugs. 2013; 22: 117-129.

[151] Oppici E, Montioli R, Dindo M, Cellini B. Natural and Unnatural Compounds Rescue Folding Defects of Human Alanine: Glyoxylate Aminotransferase Leading to Primary Hyperoxaluria Type i. Current Drug Targets. 2016; 17: 1482-1491.

[152] Zhang X, Roe SM, Hou Y, Bartlam M, Rao Z, Pearl LH, et al. Crystal structure of alanine:glyoxylate aminotransferase and the relationship between genotype and enzymatic phenotype in primary hyperoxaluria type 1 . Journal of Molecular Biology. 2003; 331: 643-652.

[153] Fodor K, Wolf J, Erdmann R, Schliebs W, Wilmanns M. Molecular requirements for peroxisomal targeting of alanineglyoxylate aminotransferase as an essential determinant in primary hyperoxaluria type 1 . Public Library of Science Biology. 2012; 10: e1001309.

[154] Cellini B, Bertoldi M, Montioli R, Paiardini A, Borri Voltattorni C. Human wild-type alanine:glyoxylate aminotransferase and its naturally occurring G82E variant: functional properties and physiological implications. The Biochemical Journal. 2007; 408: 39-50.

[155] Cellini B, Montioli R, Bianconi S, López-Alonso JP, Voltattorni $\mathrm{CB}$. Construction, purification and characterization of untagged human liver alanine-glyoxylate aminotransferase expressed in Escherichia coli. Protein and Peptide Letters. 2008; 15: 153159.

[156] Devresse A, Cochat P, Godefroid N, Kanaan N. Transplantation for Primary Hyperoxaluria Type 1: Designing New Strate- gies in the Era of Promising Therapeutic Perspectives. Kidney International Reports. 2020; 5: 2136-2145.

[157] Hoyer-Kuhn H, Kohbrok S, Volland R, Franklin J, Hero B, Beck BB, et al. Vitamin B6 in primary hyperoxaluria i: first prospective trial after 40 years of practice. Clinical Journal of the American Society of Nephrology. 2014; 9: 468-477.

[158] Scott LJ, Keam SJ. Lumasiran: first Approval. Drugs. 2021; 81: 277-282.

[159] Dindo M, Conter C, Oppici E, Ceccarelli V, Marinucci L, Cellini B. Molecular basis of primary hyperoxaluria: clues to innovative treatments. Urolithiasis. 2019; 47: 67-78.

[160] Mandrile G, van Woerden CS, Berchialla P, Beck BB, Acquaviva Bourdain C, Hulton S, et al. Data from a large European study indicate that the outcome of primary hyperoxaluria type 1 correlates with the AGXT mutation type. Kidney International. 2014; 86: 1197-1204.

[161] Oppici E, Montioli R, Cellini B. Liver peroxisomal alanine:glyoxylate aminotransferase and the effects of mutations associated with Primary Hyperoxaluria Type i: an overview. Biochimica Et Biophysica Acta - Proteins and Proteomics. 2015; 1854: 1212-1219.

[162] Mesa-Torres N, Fabelo-Rosa I, Riverol D, Yunta C, Albert A Salido E, et al. The role of protein denaturation energetics and molecular chaperones in the aggregation and mistargeting of mutants causing primary hyperoxaluria type i. Public Library of Science One. 2013; 8: e71963.

[163] Fargue S, Lewin J, Rumsby G, Danpure CJ. Four of the most common mutations in primary hyperoxaluria type 1 unmask the cryptic mitochondrial targeting sequence of alanine:glyoxylate aminotransferase encoded by the polymorphic minor allele. The Journal of Biological Chemistry. 2013; 288: 2475-2484.

[164] Danpure CJ. Primary hyperoxaluria type 1: AGT mistargeting highlights the fundamental differences between the peroxisomal and mitochondrial protein import pathways. Biochimica Et Biophysica Acta. 2006; 1763: 1776-1784.

[165] Dindo M, Mandrile G, Conter C, Montone R, Giachino D, Pelle A, et al. The ILE56 mutation on different genetic backgrounds of alanine:glyoxylate aminotransferase: Clinical features and biochemical characterization. Molecular Genetics and Metabolism. 2020; 131: 171-180.

[166] Dindo M, Oppici E, Dell’Orco D, Montone R, Cellini B. Correlation between the molecular effects of mutations at the dimer interface of alanine-glyoxylate aminotransferase leading to primary hyperoxaluria type $\mathrm{i}$ and the cellular response to vitamin B6. Journal of Inherited Metabolic Disease. 2018; 41: 263-275.

[167] Dindo M, Montioli R, Busato M, Giorgetti A, Cellini B, Borri Voltattorni C. Effects of interface mutations on the dimerization of alanine glyoxylate aminotransferase and implications in the mistargeting of the pathogenic variants F152i and i244T. Biochimie. 2016; 131: 137-148.

[168] Dindo M, Ambrosini G, Oppici E, Pey AL, O’Toole PJ, Marrison JL, et al. Dimerization Drives Proper Folding of Human Alanine: Glyoxylate Aminotransferase But Is Dispensable for Peroxisomal Targeting. Journal of Personalized Medicine. 2021; 11: 273.

[169] Dindo M, Conter C, Cellini B. Electrostatic interactions drive native-like aggregation of human alanine: glyoxylate aminostransferase. The Federation of European Biochemical Societies Journal. 2017; 284: 3739-3764.

[170] Oppici E, Fargue S, Reid ES, Mills PB, Clayton PT, Danpure CJ, et al. Pyridoxamine and pyridoxal are more effective than pyridoxine in rescuing folding-defective variants of human alanine:glyoxylate aminotransferase causing primary hyperoxaluria type i. Human Molecular Genetics. 2015; 24: 5500-5511.

[171] Oppici E, Montioli R, Dindo M, Maccari L, Porcari V, Lorenzetto A, et al. The Chaperoning Activity of Aminooxyacetic Acid on Folding-Defective Variants of Human Alanine:Glyoxylate Aminotransferase Causing Primary Hyperoxaluria Type i. ACS Chemical Biology. 2015; 10: 2227-2236. 
[172] Batson S, de Chiara C, Majce V, Lloyd AJ, Gobec S, Rea D, et al. Inhibition of D-Ala:D-Ala ligase through a phosphorylated form of the antibiotic D-cycloserine. Nature Communications. 2017; 8: 1939.

[173] Lowther J, Yard BA, Johnson KA, Carter LG, Bhat VT, Raman MCC, et al. Inhibition of the PLP-dependent enzyme serine palmitoyltransferase by cycloserine: evidence for a novel decarboxylative mechanism of inactivation. Molecular BioSystems. 2010; 6: 1682-1693.

[174] Dindo M, Grottelli S, Annunziato G, Giardina G, Pieroni M, Pampalone G, et al. Cycloserine enantiomers are reversible inhibitors of human alanine:glyoxylate aminotransferase: implications for Primary Hyperoxaluria type 1. Biochemical Journal. 2019; 476: 3751-3768

[175] Madoux F, Janovick JA, Smithson D, Fargue S, Danpure CJ, Scampavia L, et al. Development of a Phenotypic High-Content Assay to Identify Pharmacoperone Drugs for the Treatment of Primary Hyperoxaluria Type 1 by High-Throughput Screening. Assay and Drug Development Technologies. 2015; 13: 16-24.

[176] Hou S, Madoux F, Scampavia L, Janovick JA, Conn PM, Spicer TP. Drug Library Screening for the Identification of Ionophores That Correct the Mistrafficking Disorder Associated with Oxalosis Kidney Disease. Advancing the Science of Drug Discovery. 2017; 22: 887-896.
Abbreviations: ID, intrinsically disordered; IDRs, intrinsically disordered regions; PC, pharmacological chaperone; GD, Gaucher disease; LSD, lysosomal storage disorder; GBA, $\beta$-glucocerebrosidase; ERT, Enzyme Replacement Therapy; SRT, Substrate Reduction Therapy; PKU, phenylketonuria; PAH, phenylalanine hydroxylase; Phe, phenylalanine; $\mathrm{BH} 4$, tetrahydrobioptherin; $\mathrm{CaOx}$, calcium oxalate; PH1, Primary Hyperoxaluria Type I; AGT, alanine:glyoxylate aminotransferase; PLP, pyridoxal 5'phosphate; PN, pyridoxine.

Keywords: Misfolding; Parmacological chaperones; Gaucher disease; Phenylketonuria; Primary hyperoxaluria

Send correspondence to: Barbara Cellini, Department of Medicine and Surgery, University of Perugia, 06132 Perugia, Italy, E-mail: barbara.cellini@unipg.it 